\title{
Métodos de avaliação rápida da integridade ambiental aplicados à Bacia do Ribeirão Sozinha, Goiás
}

\section{Methods for rapid assessment of environmental integrity applied to Ribeirão Sozinha Basin, Goiás}

Karina Pinheiro dos Santos ${ }^{1}$; Katia Kopp ${ }^{2}$ e Wellington Nunes de Oliveira ${ }^{3}$

\author{
${ }^{1}$ Programa de Pós-Graduação em Engenharia Ambiental e Sanitária, Universidade Federal de Goiás, GO, Brasil \\ karina.pinheiro.santos@gmail.com
}

${ }^{2}$ Programa de Pós-graduação em Engenharia do Meio Ambiente, Universidade Federal de Goiás, GO, Brasil kakopp@gmail.com

${ }^{3}$ Programa de Pós-graduação em Engenharia do Meio Ambiente, Universidade Federal de Goiás, GO, Brasil wellington.wno@gmail.com

Recebido: 10/04/14 - Revisado: 24/09/14 - Aceito: 14/11/14

\begin{abstract}
RESUMO
O monitoramento ambiental em bacias hidrográficas depende de diagnósticos ambientais confiáveis para o melhor gerenciamento dos recursos naturais. Assim, este estudo teve o objetivo de realizar o diagnóstico ambiental da Bacia Hidrográfica do Ribeirão Sozinha, relacionando e identificando os principais impactos na bacia hidrográfica e nos cursos d'água pela aplicaşão de uma matriz de impacto ambiental e de um protocolo de avaliação rápida. Este estudo também buscou identificar e avaliar os principais usos e ocupações do solo que poderiam causar impactos nos recursos hídricos, por meio da utilização de geotecnologias, além de avaliar o emprego conjunto desses três métodos no estudo da bacia hidrográfica selecionada. Com o protocolo, foi observado que 33,3\% dos trechos se enquadraram em "naturais" e 66,7\% em "alterados" ou "impactados"; já a aplicação da matriz indicon que a maioria dos trechos sofre impactos de "grande" ou "média" intensidade. O mapa de uso do solo evidenciou que as atividades antrópicas predominantes nesta bacia são a agricultura e a pecuária e que a maioria dos impactos nos recursos hídricos e na bacia tem relação com estas atividades. Pode-se afirmar que há uma complementariedade entre as metodologias utilizadas e, apesar da necessidade de adequações, a utilização conjunta pode ser uma opção viável para o monitoramento ambiental.
\end{abstract}

Palavras Chave: Matriz de Leopold. Protocolo de avaliação rápida. Usos e ocupação do solo. Recursos hidricos. Impacto ambiental. Monitoramento ambiental

\begin{abstract}
Environmental monitoring in watersheds depends on reliable environmental diagnostics for better management of natural resources. Thus, this study aimed to perform the environmental assessment of the Ribeirão Sozinha Basin, by relating and identifying the main impacts in the watershed and fluvial environmental by applying a matrix of environmental impact and a rapid assessment protocol. This study also aimed to identify and evaluate the main use and occupation of the soil that could impact water resources, through the use of geotechnologies, and also evaluate the combined use of these three methodologies in the study of selected watershed. Using the protocol it was observed that about 33.3\% of the stretches are considered "natural" and 66.7\% are "modified" or "impacted". Already the application of the matrix indicated that the majority of stretches suffer impacts of "bigh" or "medium" intensity. The land use map that showed the greatest anthropogenic activities in this basin are agriculture and livestock and the majority of impacts on water resources and in the basin are related to these activities. It can be stated that the methodologies used are complementary, and despite the need for adaptations, combined use can be a viable option for environmental monitoring.
\end{abstract}

Keywords: Leopold matrix. Rapid assessment protocol. Land use. Water resources. Environmental impact. Environmental monitoring 


\section{INTRODUÇÃO}

A utilização dos recursos naturais apenas para fins econômicos tem gerado graves problemas ao meio ambiente, já que sua exploração é realizada sem o uso de metodologias que impeçam a degradação e o desequilíbrio dos ambientes naturais.

Em termos de planejamento ambiental, a bacia hidrográfica ou suas subdivisões são consideradas como unidades de referência para a observação dos principais impactos ambientais sofridos por sua área de drenagem, visto ser ela resultado da interação entre os cursos d'água, os recursos naturais e as atividades antrópicas ali desenvolvidas.

Algumas modificações no uso do solo, como o desmatamento para a agricultura e a pastagem, têm tido severo impacto sobre os recursos hídricos (SUGA; TANAKA, 2013). Assim, os desequilíbrios ambientais intensos suportados pela bacia hidrográfica propiciam alterações ecossistêmicas que necessitam ser avaliadas de maneira integrada para que se identifiquem os principais impactos no ambiente.

Diante disto, estudos integrados que contemplem o diagnóstico dos cursos d'água e a avaliação dos usos dos recursos naturais e das principais atividades antropogênicas podem gerar dados importantes para o planejamento e o monitoramento ambiental. Portanto, ressalta-se a necessidade de diagnósticos ambientais integrados, fáceis, objetivos, de qualidade e de baixo custo para o êxito de programas de monitoramento, preservação ou recuperação de bacias hidrográficas.

Segundo Fernandes et al. (2011), o monitoramento ambiental em bacias hidrográficas busca caracterizar aspectos relevantes que possibilitem diagnosticar as mudanças no uso e na ocupação do solo, tornando possível avaliar os efeitos das atividades humanas exercidas nas bacias hidrográficas e, consequentemente, sobre os ecossistemas. Por isso, é recomendado monitorar variáveis ambientais que sejam sensíveis às alterações que possam vir a acontecer.

Para tanto, Leite et al. (2012) afirmam que análises de uso do solo dispõem de importantes instrumentos dentro das geotecnologias que possibilitam a geração de valorosas informações espaciais e temporais, diagnósticos e prognósticos relevantes em análises naturais. O sensoriamento remoto, técnica que compõe as geotecnologias, surgiu com a finalidade de monitorar determinado espaço à distância, o que possibilita uma maior eficácia em estudos ambientais.

Costa, Silva e Mattos (2013) afirmam que uma ferramenta muito empregada para a identificação de impactos ambientais em bacias hidrográficas são as matrizes de impacto ambiental. Segundo Sánchez (2006), elas permitem elencar as principais atividades ou ações antrópicas e os componentes ou elementos do sistema ambiental ou, ainda, processos ambientais, objetivando identificar as possíveis interações entre eles. Para esse autor, a matriz de Leopold dá subsídio ao planejamento ambiental, importantíssimo para a conservação dos recursos naturais e a organização das sociedades.

$\mathrm{O}$ uso de metodologias que auxiliem no processo de avaliação dos recursos hídricos - e que também colaborem na tomada de decisões nos processos de gestão ambiental - é muito importante, principalmente em bacias hidrográficas inseridas em áreas urbanas e utilizadas para o abastecimento público, já que a urbanização e a ação antrópica, de maneira geral, podem gerar o comprometimento da qualidade da água e das condições dos habitats dos recursos hídricos ali inseridos.

Um exemplo desse tipo de metodologia é o Protocolo de Avaliação Rápida da Diversidade de Habitats, proposto por Callisto et al. (2002), capaz de informar o grau de conservação dos cursos d'água por meio da avaliação das condições ambientais de trechos de rios. Esse protocolo é uma metodologia muito utilizada no Brasil e serve para estabelecer as relações de estrutura e funcionamento entre os ecossistemas aquáticos e a bacia de drenagem. Além disso, essa ferramenta tem o objetivo de contribuir para o manejo e a conservação destes ambientes (CALLISTO et al., 2002).

Levando-se em conta que bacias hidrográficas que compreendem mananciais utilizados para o abastecimento humano em regiões metropolitanas devem ser preservadas para garantir a qualidade e a disponibilidade de água para uma grande demanda populacional, e diante da necessidade de estudos que procurem medir a qualidade desses rios, bem como verificar o quanto as atividades antropogênicas os têm afetado, pesquisas como esta são imprescindíveis. Dessa maneira, o objetivo deste artigo foi realizar o diagnóstico ambiental da Bacia Hidrográfica do Ribeirão Sozinha, identificando e relacionando os principais impactos na bacia hidrográfica e nos cursos d’água, além de levantar e avaliar os principais usos e ocupações do solo que poderiam causar possíveis impactos nos recursos hídricos, com o intuito de avaliar a utilização conjunta das três metodologias no levantamento do estado ambiental da bacia em estudo.

\section{MATERIAIS E MÉTODOS}

\section{Área de estudo}

A área de estudo deste artigo compreende a Bacia Hidrográfica do Ribeirão Sozinha, localizada no estado de Goiás, no Bioma Cerrado, mais precisamente na região centro-sul, entre os paralelos $16^{\circ} 00^{\prime} 00^{\prime \prime}$ e $18^{\circ} 00^{\prime} 00^{\prime}$ " sul e $48^{\circ} 00^{\prime} 00^{\prime \prime}$ e $50^{\circ} 00^{\prime} 00^{\prime \prime}$ leste. Essa bacia hidrográfica possui uma área de $262,92 \mathrm{~km}^{2}$ e abrange, parcialmente, os municípios de Caldazinha, Bonfinópolis, Anápolis, Goianápolis, Senador Canedo, Bela Vista de Goiás e Leopoldo de Bulhões. A bacia em questão abarca, então, parte de seis cidades que compõem a região metropolitana de Goiânia. Além disso, nesta bacia, mais exatamente no Ribeirão Sozinha, é realizada a captação de água para o abastecimento público da cidade de Goianápolis.

Segundo Souza e Lima (2013), a bacia do Ribeirão Sozinha é uma área de grande relevância em termos de produção agrícola, devido, principalmente, a importante região em que está inserida. Tanto seus solos quanto sua rede de drenagem são amplamente utilizados para o cultivo de produtos agrícolas e criação de gado, com vistas a atender mercados como a cidade de Anápolis e a Região Metropolitana de Goiânia, que juntas possuem uma população superior a dois milhões de habitantes. 


\section{Coleta de dados}

A coleta de dados foi realizada por meio de duas visitas a campo, no período entre outubro de 2013 e janeiro de 2014. Foram selecionados doze pontos de coleta, com o intuito de se obter mais informações da área total da bacia, levando-se em conta a possibilidade de acesso (Tabela 1, Figura 1). Em campo, houve a aplicação da matriz de Leopold e do protocolo de avaliação rápida por um avaliador treinado. Ademais, foram realizados o registro fotográfico e o registro da localização geográfica dos pontos amostrais, além de terem sido feitas anotações para melhor caracterizar a situação dos locais de coleta.

Tabela 1 - Localização dos pontos amostrais visitados

\begin{tabular}{|c|c|c|}
\hline Sigla & Trecho & Localização \\
\hline G0I1 & Afluente 1 & $16^{\circ} 25^{\prime} 02,9^{\prime \prime} \mathrm{S} ; 49^{\circ} 00^{\prime} 24,5^{\prime \prime} \mathrm{W}$ \\
\hline G0I2 & Rib. Sozinha & $16^{\circ} 29^{\prime} 09,8^{\prime \prime} \mathrm{S} ; 48^{\circ} 59^{\prime} 50,4 \mathrm{~W}$ \\
\hline G0I3 & Rib. Sozinha & $16^{\circ} 27^{\prime} 50,4^{\prime \prime} \mathrm{S} ; 48^{\circ} 59^{\prime} 00^{\prime \prime} \mathrm{W}$ \\
\hline G0I4 & Rib. Sozinha & $16^{\circ} 31^{\prime} 45,8^{\prime \prime} \mathrm{S} ; 48^{\circ} 59^{\prime} 41,7^{\prime \prime} \mathrm{W}$ \\
\hline G0I5 & Rib. Sozinha & $16^{\circ} 34^{\prime} 6.60^{\prime \prime} \mathrm{S} ; 49^{\circ} 1^{\prime} 53.20^{\prime \prime} \mathrm{W}$ \\
\hline G0I6 & Rib. Sozinha & $16^{\circ} 36^{\prime} 52,2^{\prime \prime} \mathrm{S} ; 49^{\circ} 00^{\prime} 11,0^{\prime \prime} \mathrm{W}$ \\
\hline G0I7 & Afluente 2 & $16^{\circ} 37^{\prime} 35,1^{\prime \prime} \mathrm{S} ; 48^{\circ} 57^{\prime} 55,7^{\prime \prime} \mathrm{W}$ \\
\hline G0I8.1 & Rib. Sozinha & $16^{\circ} 42^{\prime} 39.1^{\prime \prime} \mathrm{S} ; 49^{\circ} 02^{\prime} 47.9^{\prime \prime} \mathrm{W}$ \\
\hline G0I9.1 & Rib. Sozinha & $16^{\circ} 43^{\prime} 02.9^{\prime \prime} \mathrm{S} ; 49^{\circ} 03^{\prime} 08.4^{\prime \prime} \mathrm{W}$ \\
\hline G0I10.1 & Rib. Sozinha & 43’ 47.6”S; 4903’ 18.6” W \\
\hline G0I11.1 & Rib. Sozinha & $16^{\circ} 42^{\prime} 25.0^{\prime \prime} \mathrm{S} ; 49^{\circ} 02^{\prime} 35.0^{\prime \prime} \mathrm{W}$ \\
\hline Captação & Rib. Sozinha & $16^{\circ} 30^{\prime} 4.88^{\prime \prime} \mathrm{S}, 49^{\circ} 0^{\prime} 11.08^{\prime \prime} \mathrm{W}$ \\
\hline
\end{tabular}

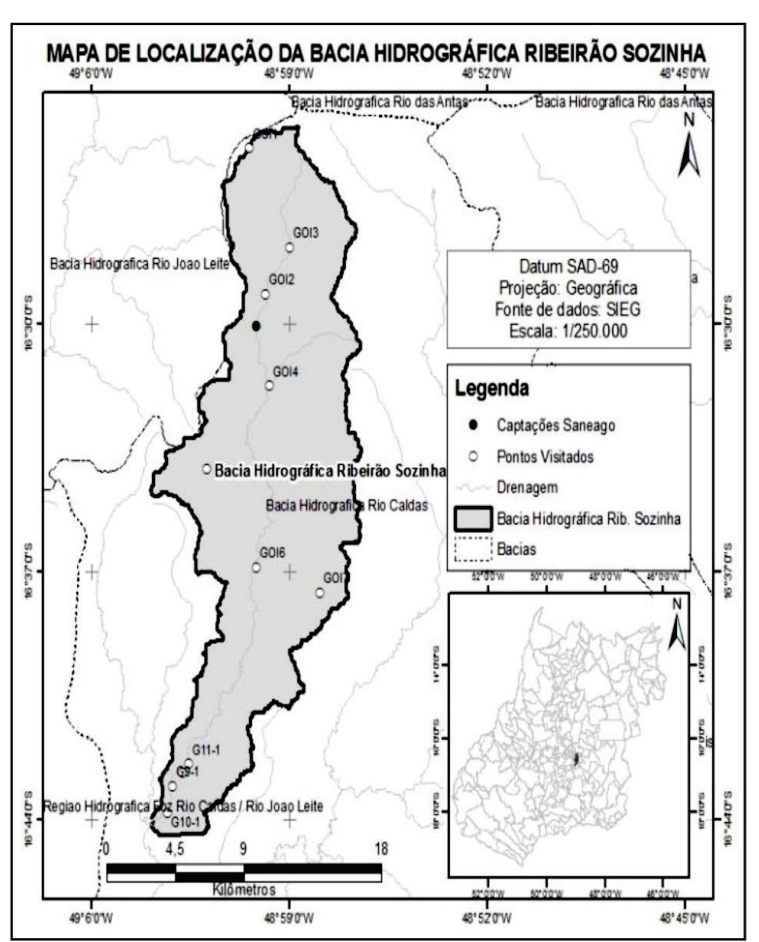

Figura 1 - Mapa de localização da Bacia Hidrográfica do Ribeirão Sozinha e dos pontos amostrais visitados

\section{Elaboração do mapa de usos do solo}

Para manipulação das informações especializadas e dos dados vetoriais em ambiente computacional, foi utilizado o software ArcGis 9.3. Para a organização dos mapas de uso do solo foram investigados dados no site do Sistema Estadual de Estatística e de Informações Geográficas de Goiás (SIEG-GO). As informações empregadas constituíram-se em dados vetoriais, com escalas de 1:100.000 a 1:500.000, que determinavam as drenagens, os usos do solo, as bacias hidrográficas, os limites municipais e a captação de água para abastecimento público da cidade de Goianápolis, realizado pela empresa de Saneamento do Estado de Goiás (Saneago).

\section{Diagnóstico ambiental}

O diagnóstico ambiental dos rios foi feito pelo Protocolo de Avaliação Rápida da Integridade Ecológica proposto por Callisto et al. (2002). O protocolo é dividido em duas partes. A primeira tem o objetivo de caracterizar trechos das bacias em estudo e, também, a intensidade dos impactos ambientais decorrentes das atividades humanas em sua região ripária. Para isso, dez parâmetros são avaliados e para cada um é atribuída uma pontuação de 0 a 4 . A segunda parte do protocolo visa avaliar as condições dos habitats e o nível de conservação das condições naturais, avaliando doze parâmetros e conferindo-lhes uma pontuação que pode variar de 0 a 5 , dada a partir daobservação visual das condições dos habitats. O resultado final do protocolo se dará com o somatório de todos os pontos obtidos e indicará o estado de conservação das condições ecológicas dos trechos estudados, em que de 0 a 40 representa um trecho impactado, de 41 a 60 trechos alterados, e acima de 61 os trechos naturais (CALLISTO et al., 2002).

Já a matriz de Leopold foi usada para identificar os impactos ambientais negativos na bacia. A sua adaptação seguiu orientações do trabalho de Padovesi-Fonseca et al. (2010). As matrizes foram aplicadas na região adjacente aos trechos dos rios avaliados por meio do protocolo de avaliação rápida.

Para a adaptação da matriz foram levantados os impactos ambientais mais comuns que poderiam ocorrer nesta bacia, com base nos mapas de uso e ocupação do solo. De forma a interpretar melhor os dados, somente os impactos mais relevantes em termos de ocorrência, intensidade e extensão foram avaliados para cada ponto amostral e dispostos na matriz. A partir da observação em campo, atribuiu-se valores para informações de magnitude (de 0 a 10) e importância (de 0 a 10). O resultado da matriz se dá por meio do produto com os valores de magnitude e importância de cada impacto. Um resultado de 0-35 é considerado de pequena intensidade, de 36-65 de média intensidade e de 66-100 de grande intensidade.

\section{RESULTADOS E DISCUSSÃO}

Conforme o mapa de uso dos solos (Figura 2), percebe-se que a atividade agrícola foi considerada o uso do solo predominante nesta bacia, com $67,06 \%$ da sua área total. 


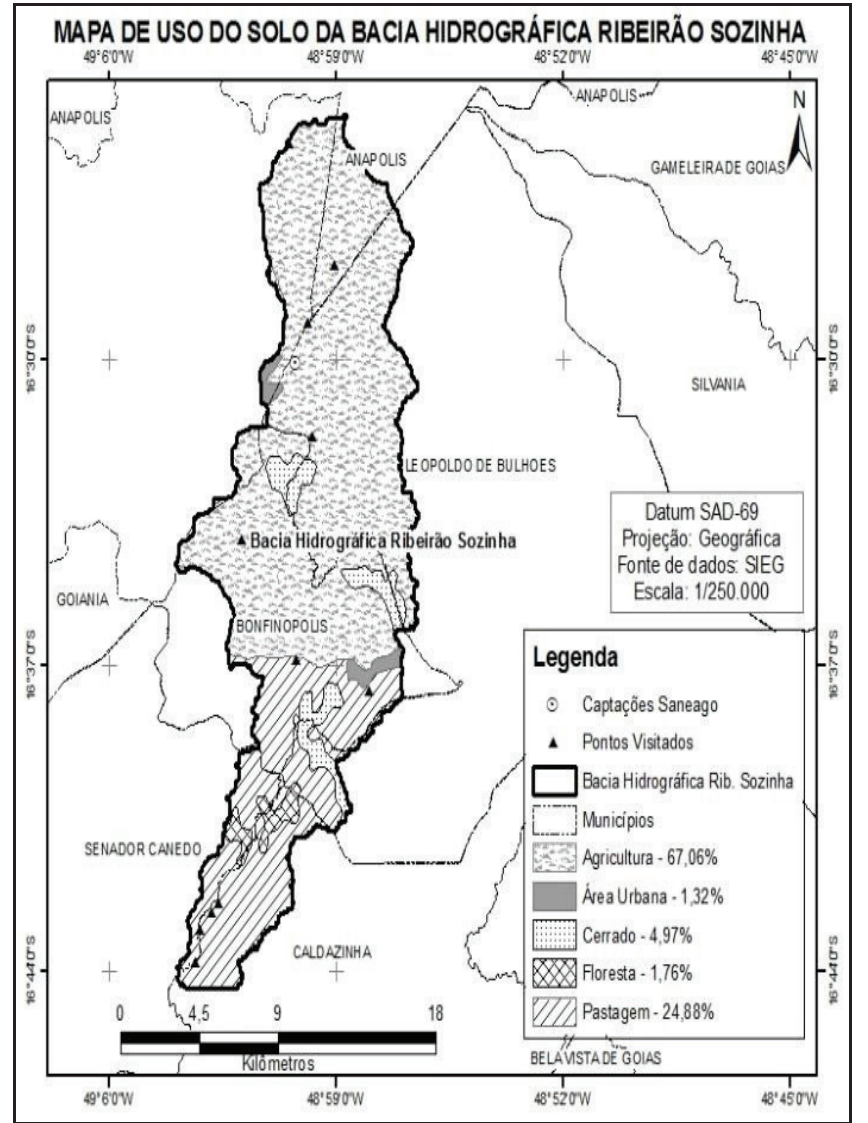

Figura 2 - Mapa de uso do solo da Bacia Hidrográfica do Ribeirão Sozinha, Goiás

Segundo informações do Instituto Mauro Borges (IMB, 2013), as cidades que compreendem esta bacia foram consideradas, em 2011, grandes produtoras de milho, sorgo, soja, canade-açúcar e tomate. O estado de Goiás foi considerado, no ano de 2012, o primeiro maior produtor de sorgo e tomate do Brasil (IBGE, 2013). Já com relação à produção de cana-de-açúcar, milho e soja, o estado figurou como o terceiro maior produtor entre as unidades da federação (IMB, 2013).

Dentre as consequências danosas da agricultura para os recursos hídricos pode-se ressaltar a irrigação, pois parte da água nela utilizada volta ao sistema hídrico por meio da infiltração no solo. Ao atingir o lençol freático, parte é absorvida pela planta, outra evapora para a atmosfera. $\mathrm{Na}$ maioria das regiões este volume de água não retorna ao local evaporado, mas entra no sistema geral de circulação da atmosfera. No entanto, isso pode ser um grave problema ambiental em regiões de limitada disponibilidade de água frente à demanda.

Silva (2007) afirma que mais de 90\% da área cultivada na região dos Cerrados é irrigada por meio de pivô central, sendo o remanescente irrigado por gotejamento. Isso demonstra que há um possível impacto ambiental nas águas da região devido a grande demanda de água necessária para a irrigação.

O desmatamento e as queimadas são práticas corriqueiras estabelecidas anteriormente à implantação das monoculturas. Para os recursos hídricos, estas técnicas são muito prejudiciais, uma vez que a vegetação nativa coopera para a regulação do regime natural de chuva, protege o solo da erosão e impede que os rios e lagos sejam assoreados pelo sedimento que percola sobre o solo.

A retirada da vegetação nativa e a inserção da monocultura podem produzir profundas alterações ambientais, bem como resultar em mudanças climáticas locais, regionais e até mesmo globais. Além disso, estudos em áreas de produção de cana-de-açúcar indicam um aumento da amplitude térmica destas em comparação a áreas com Cerrado (GOMES et al., 2009).

Além disso, a exploração agrícola pela utilização e manejo impróprio do solo podem levar a uma intensificação da deterioração dos ecossistemas aquáticos (DILL, 2007). Diversas podem ser as implicações observadas pelo uso de agrotóxico ou fertilizante em relação aos recursos hídricos, tais como: toxicidade e bioacumulação nos organismos aquáticos e sedimento, o que prejudica a cadeia alimentar e reduz a biodiversidade local; a acumulação nos organismos aquáticos, que contamina as fontes alimentares da população humana; a eutrofização do corpo hídrico; a contaminação direta da população humana pelo consumo de água; a toxicidade e bioacumulação para culturas irrigadas com água contaminada (OLIVEIRA-FILHO, 2002).

Soares e Porto (2007) destacam que a contaminação de coleções de água superficiais e subterrâneas tem um potencial extremamente poluente, pois, se o local onde se aplicou o agrotóxico for próximo a um manancial hídrico que abastece uma cidade, a qualidade dessa água captada também deverá estar comprometida. Na bacia hidrográfica em estudo observa-se que este pode ser um sério impacto ambiental aos cursos d'água, já que a captação da água utilizada para o abastecimento humano da cidade de Goianápolis está inserida em uma região de intensa produção agropecuária.

Conforme informações do IMB (2013) no ano de 2012, o estado de Goiás foi considerado o $3^{\circ}$ maior produtor de rebanho bovino do Brasil. Isso confirma as informações apresentadas na Figura 2 de que as pastagens contribuem para o segundo maior uso de solos no estado, com 24,88\% da área total da bacia.

Outro problema ambiental relativo à utilização intensiva de pastagem para a criação bovina diz respeito à compactação do solo gerada pelo deslocamento dos rebanhos. O solo compactado impede a infiltração da água e intensifica o escoamento superficial, podendo gerar erosões e, por consequência, o carreamento de sedimento para os recursos hídricos. Este sedimento, ao ser carreado para o corpo d'água, pode conter determinada carga de nutrientes, hormônios, metais pesados e organismos patógenos (provenientes do esterco), causando a poluição das águas.

Além das implicações ambientais provenientes do desmatamento, discutidas anteriormente, um fato que agrava o dano ambiental causado aos recursos hídricos é o desmatamento de áreas de preservação permanente para fins de agricultura ou pastagem. De fato, aproximadamente $24.000 \mathrm{~km}^{2}$ de ambientes ripários se encontram desprotegidos no estado de Goiás, o que implica na perda da qualidade dos recursos hídricos (BONNET et al., 2007).

Sano et al. (2010) afirmam que cerca de 50\% da área original que compreende o Bioma Cerrado foi desmatada para a conversão em agricultura ou pastagem, o que equivale a uma área de um milhão de $\mathrm{km}^{2}$. Assim, o Cerrado e as florestas ocu- 
Tabela 2 - Resultado da aplicação da matriz adaptada de Leopold em todos os trechos da bacia do Ribeirão Sozinha, Goiás

\begin{tabular}{|c|c|c|c|c|c|c|c|c|c|c|c|c|c|c|c|c|c|c|c|c|c|c|c|c|}
\hline \multirow[b]{2}{*}{ Impactos } & \multicolumn{24}{|c|}{ Trechos e resultados } \\
\hline & $\underset{0}{\overline{0}}$ & 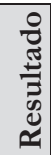 & $\underset{\circlearrowleft}{O}$ & 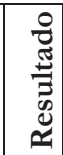 & 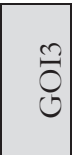 & 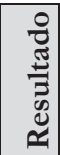 & $\underset{\circlearrowleft}{\Delta}$ & 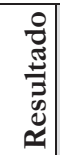 & $\stackrel{10}{0}$ & 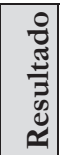 & 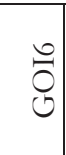 & 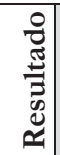 & $\stackrel{\curvearrowright}{\widehat{O}}$ & 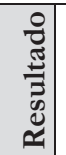 & $\begin{array}{c}\overrightarrow{0} \\
\stackrel{0}{0} \\
0\end{array}$ & 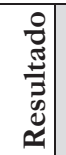 & $\begin{array}{c}\overrightarrow{0} \\
\overrightarrow{0} \\
0\end{array}$ & 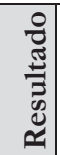 & $\begin{array}{l}\overrightarrow{0} \\
\stackrel{0}{0} \\
0 \\
0\end{array}$ & 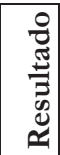 & 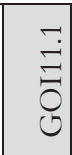 & 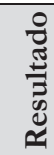 & 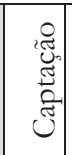 & 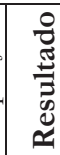 \\
\hline Danos a APP & 100 & G & 100 & G & 100 & $\mathbf{G}$ & 54 & $\mathbf{M}$ & 100 & G & 100 & G & 90 & G & 80 & G & 90 & G & 64 & $\mathbf{M}$ & 80 & G & 70 & G \\
\hline $\begin{array}{c}\text { Fauna e flora } \\
\text { exótica }\end{array}$ & 00 & G & 100 & G & 64 & $\mathbf{M}$ & - & - & 100 & G & 40 & $\mathbf{M}$ & 48 & $\mathbf{M}$ & 81 & G & 56 & $\mathbf{M}$ & 50 & $\mathbf{M}$ & 25 & $\mathbf{P}$ & 50 & $\mathbf{M}$ \\
\hline $\begin{array}{r}\text { Comp } \\
\text { do }\end{array}$ & 80 & G & 60 & $\mathbf{M}$ & 80 & G & 35 & $\mathbf{P}$ & 72 & G & 10 & $\mathbf{P}$ & 30 & $\mathbf{P}$ & 9 & $\mathbf{P}$ & 63 & $\mathbf{M}$ & 72 & G & 25 & $\mathbf{P}$ & 65 & $\mathbf{M}$ \\
\hline $\begin{array}{r}\text { Dras } \\
\text { Bo }\end{array}$ & - & - & - & - & 48 & $\mathbf{M}$ & - & - & 36 & M & 40 & $\mathbf{P}$ & 100 & G & 80 & G & - & - & - & - & 18 & $\mathbf{P}$ & 100 & G \\
\hline Agri & 35 & $\mathbf{P}$ & 90 & G & 100 & G & 64 & $\mathbf{M}$ & 100 & G & 10 & $\mathbf{P}$ & - & - & 36 & $\mathbf{M}$ & - & - & 10 & $\mathbf{P}$ & - & - & 65 & $\mathbf{M}$ \\
\hline Pecu & 100 & G & 80 & $\mathbf{G}$ & 100 & G & 80 & $\mathbf{G}$ & 80 & G- & 35 & $\mathbf{P}$ & 60 & $\mathbf{M}$ & 63 & $\mathbf{M}$ & 72 & G & 80 & G & 42 & $\mathbf{M}$ & 90 & $\mathbf{G}$ \\
\hline & 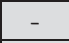 & - & 64 & $\mathbf{M}$ & 6 & $\mathbf{P}$ & 1 & $\mathbf{P}$ & 35 & $\mathbf{P}$ & 32 & $\mathbf{P}$ & 100 & $\mathbf{G}$ & 50 & $\mathbf{M}$ & - & - & 72 & $\mathrm{G}$ & - & - & 60 & $\mathbf{M}$ \\
\hline $\mathrm{p}$ & 25 & $\mathbf{P}$ & 60 & $\mathbf{M}$ & 4 & $\mathbf{P}$ & 4 & $\mathbf{P}$ & 12 & $\mathbf{P}$ & 60 & $\mathbf{M}$ & 90 & G & 54 & $\mathbf{M}$ & 60 & $\mathbf{P}$ & 18 & $\mathbf{P}$ & 40 & $\mathbf{M}$ & 40 & $\mathbf{M}$ \\
\hline Cerca & - & - & 48 & $\mathbf{M}$ & 4 & $\mathbf{P}$ & 3 & $\mathbf{P}$ & 2 & $\mathbf{P}$ & 10 & $\mathbf{P}$ & - & - & 10 & $\mathbf{P}$ & - & - & - & - & - & -- & 5 & $\mathbf{P}$ \\
\hline & 72 & $\mathbf{G}$ & - & - & - & - & - & - & 80 & $\mathrm{G}$ & 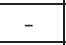 & - & 40 & $\mathbf{M}$ & - & - & - & - & - & - & - & - & 56 & $\mathbf{M}$ \\
\hline & 80 & G & 24 & $\mathbf{P}$ & - & - & 1 & $\mathbf{P}$ & 48 & $\mathbf{M}$ & 60 & $\mathbf{M}$ & 100 & G & 70 & G & 63 & $\mathbf{P}$ & - & - & - & - & 60 & M \\
\hline Automóveis & 25 & $\mathbf{P}$ & 40 & $\mathbf{M}$ & 2 & $\mathbf{P}$ & 2 & $\mathbf{P}$ & 2 & $\mathbf{P}$ & 100 & $\mathbf{G}$ & 90 & G & 15 & $\mathbf{P}$ & 35 & $\mathbf{M}$ & - & - & - & - & 20 & $\mathbf{P}$ \\
\hline Canalizações & - & - & - & - & - & - & - & - & - & - & $\begin{array}{ll}- \\
\end{array}$ & - & 100 & $\mathbf{G}$ & 90 & G & - & - & - & - & - & - & 25 & $\mathbf{P}$ \\
\hline Lixo & 15 & $\mathbf{P}$ & 32 & $\mathbf{P}$ & 36 & $\mathbf{M}$ & - & - & - & - & 24 & $\mathbf{P}$ & 95 & $\mathbf{G}$ & 35 & $\mathbf{P}$ & - & - & - & - & - & - & - & - \\
\hline $\begin{array}{c}\text { Despejo de } \\
\text { efluente }\end{array}$ & . & - & - & - & - & - & - & - & - & - & - & - & 56 & $\mathbf{M}$ & - & - & - & - & - & - & - & - & - & - \\
\hline $\begin{array}{c}\text { Aglomeração } \\
\text { urbana }\end{array}$ & 2 & $\mathbf{P}$ & - & - & 1 & $\mathbf{P}$ & - & - & - & - & - & - & 60 & $\mathbf{M}$ & 40 & $\mathbf{M}$ & 28 & $\mathbf{P}$ & - & - & 2 & $\mathbf{P}$ & 1 & $\mathbf{P}$ \\
\hline Indústria & - & - & - & - & - & - & & - & - & - & 20 & $\mathbf{P}$ & - & - & - & - & - & - & - & - & - & - & - & - \\
\hline Agrotóxicos & 40 & $\mathbf{M}$ & 64 & $\mathbf{M}$ & 100 & $\mathrm{G}$ & 35 & $\mathbf{P}$ & 80 & $\mathrm{G}$ & - & - & 56 & $\mathbf{M}$ & 15 & $\mathbf{P}$ & - & - & 36 & $\mathbf{M}$ & - & - & 30 & $\mathbf{P}$ \\
\hline
\end{tabular}

Siglas: P:pequena intensidade; M: média intensidade; G: grande intensidade; APP: área de preservação permanente

pam somente $6,93 \%$ de toda a área da microbacia do Ribeirão Sozinha (Figura 2).

Segundo Souza e Lima (2013), 48,19\% da área da bacia do Ribeirão Sozinha se apresenta muito ou extremamente suscetível à erosão laminar, fato que deve ser levado em consideração, já que a erosão degrada o solo e assoreia os mananciais de água.

A ocupação urbana nesta bacia foi considerada o menor uso do solo, com $1,32 \%$ da sua área total. De acordo com Lucas e Cunha (2011), os principais impactos decorrentes do desenvolvimento de uma área urbana sobre os processos hidrológicos estão ligados à forma de ocupação do solo e também ao aumento das superfícies impermeáveis. Estes autores afirmam que, além deles, a disposição indevida de resíduos sólidos, a geração de efluentes domésticos e industriais também causam alterações negativas nos ecossistemas aquáticos. De fato, nessa bacia foram verificados vários pontos de disposição inadequada de resíduos sólidos (veja Tabela 2) que podem afetar a qualidade dos recursos hídricos e interferir nos processos ecológicos naturais.

Souza et al. (2013) destacam que as cidades brasileiras, em geral, têm sofrido, sistematicamente, com as falhas dos sistemas de drenagem, com grandes prejuízos materiais e risco à saúde e à vida da população. A impermeabilização dos solos, por exemplo, tem impacto significativo sobre as vazões das bacias. A consequência mais evidente é o aumento do escoamento superficial, que implicará em uma menor infiltração no subsolo, gerando uma menor recarga do aquífero, além da redução de sua capacidade de absorver cargas poluidoras. Já o aumento do escoamento superficial em períodos de chuva pode gerar processos erosivos e assoreamento (FINOT'TI et al., 2009).

Em relação ao diagnóstico ambiental, pela adaptação da matriz de Leopold pode-se verificar que os resultados variaram de 1 a 100 (Tabela 2). Neste trabalho, sua utilização foi viável no sentido de que foi possível elencar e quantificar as atividades antrópicas ocorridas em cada trecho estudado, além de possibilitar uma visão mais abrangente de qual seria a realidade da situação dos impactos antrópicos nas regiões em estudo.

Nota-se que a maioria dos trechos estudados tem impactos considerados de "grande" ou "média" intensidade. A matriz possibilitou uma análise sistêmica das ações antrópicas.

$\mathrm{Na}$ Tabela 2, pode-se ver que nos trechos GOI4 e GOI6 a maioria dos impactos é de "pequena" intensidade. $\mathrm{Na}$ região do trecho GOI4, parte da vegetação é nativa e parte está desmatada para pastagem (Figura 3). No trecho GOI6, na montante do ribeirão há uma indústria de pequeno porte, que capta a água deste por meio de uma bomba d'água (Figura 4).

Nos trechos GOI1, GOI3 e GOI5, o resultado da matriz indicou que grande parte dos impactos foi de "pequena" e "grande" intensidade. No trecho GOI1, o córrego possui diversos represamentos e grande parte da área de preservação permanente foi destruída para atividade agropecuária (Figura 5). Já o trecho GOI5 está inserido em uma área de plantação de tomates (Figura 6, conforme a seta), há barramentos no corpo 


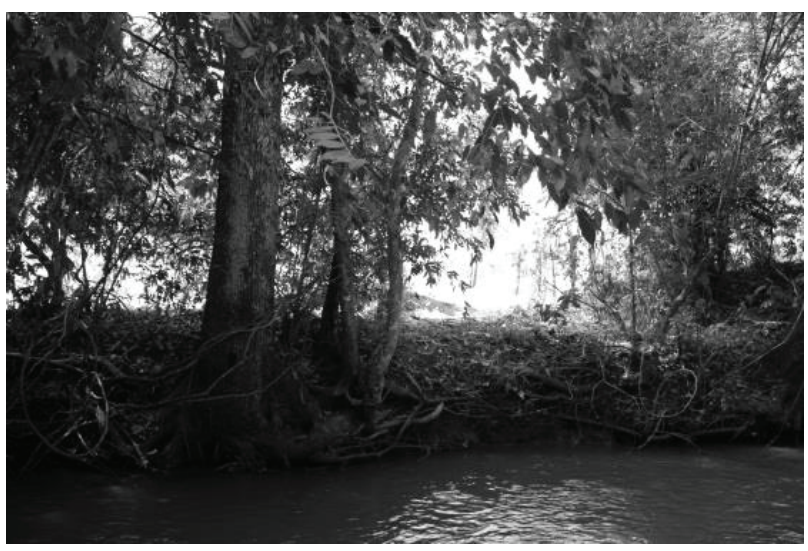

Figura 3 - Trecho GOI4, situado na Bacia do Ribeirão Sozinha, em Goiás, com mata ciliar desmatada e leito do ribeirão preservado

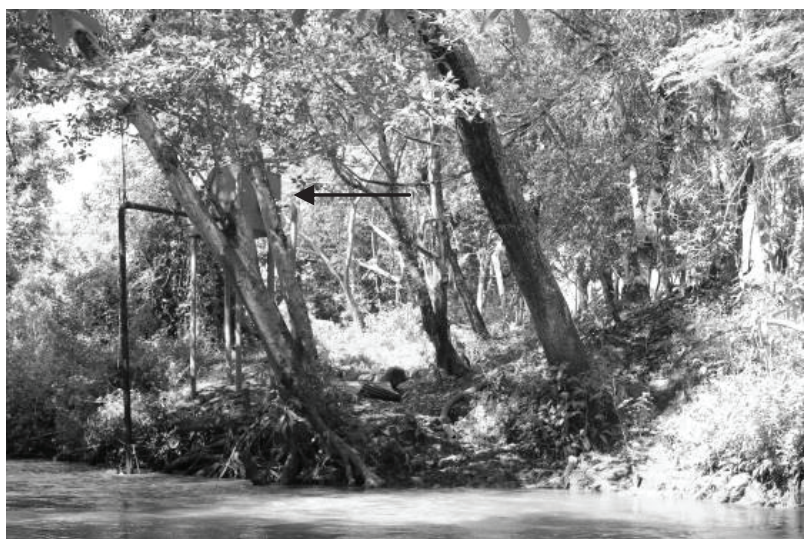

Figura 4 - Trecho GOI6, situado na Bacia do Ribeirão Sozinha, em Goiás, com bomba mecânica (seta)

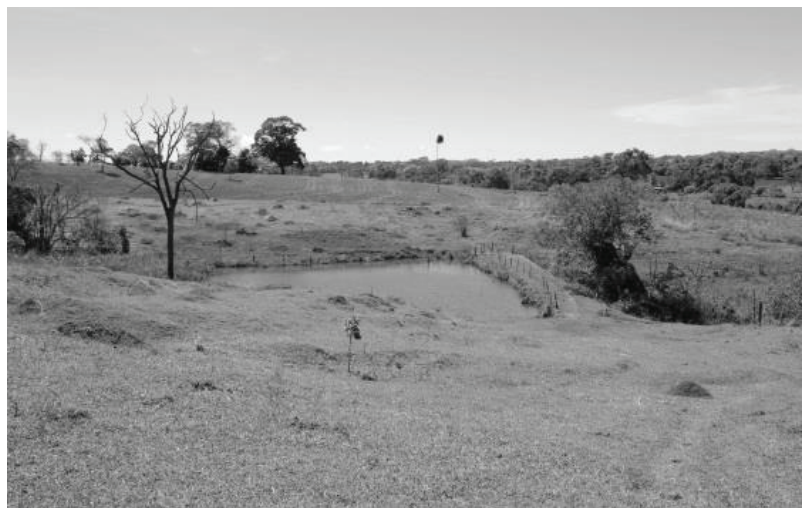

Figura 5 - Trecho GOI1, situado na Bacia do Ribeirão Sozinha, em Goiás, possui as margens do córrego desmatadas e córrego represado

hídrico que está assoreado e as margens foram desmatadas e estão instáveis. Na região do ponto GOI3 há a presença de bombas (mecânicas) e encanamentos de água, utilizados para a irrigação de uma lavoura de tomate (Figura 7). Neste trecho havia muitos tonéis de óleo dispostos às margens do ribeirão.

Nos trechos GOI2, GOI7 e GOI10.1 predominaram impactos de "grande" e "média" intensidade, como pode ser visto na Tabela 1. No ponto amostral GOI2 há muitas plantações

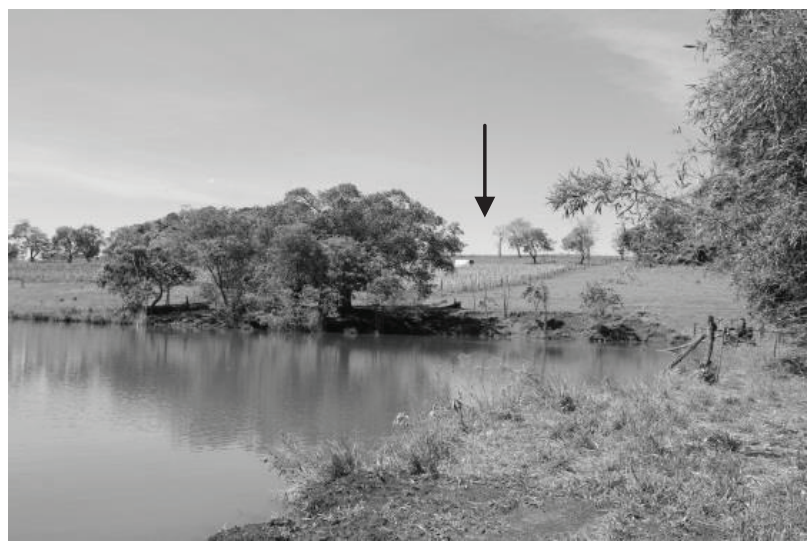

Figura 6 - Trecho GOI5, localizado na Bacia do Ribeirão Sozinha, Goiás, com margens desmatadas, acima se vê a plantação de tomate (seta)

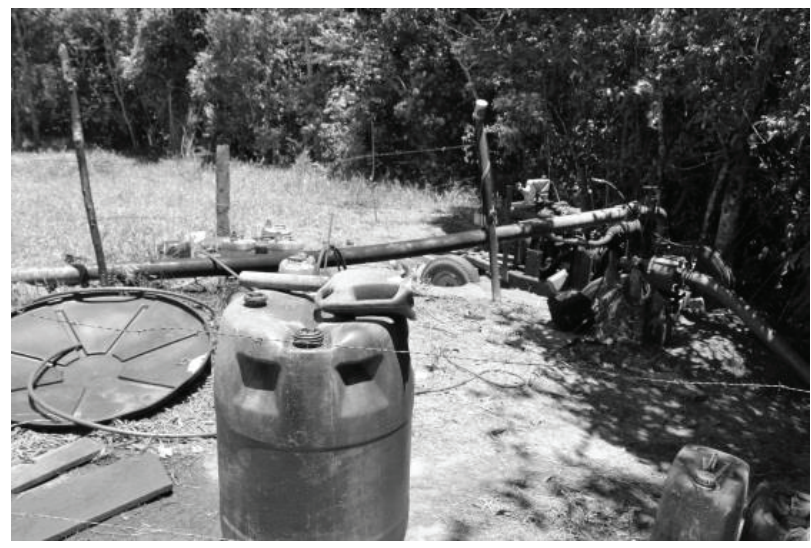

Figura 7- No trecho GOI3, localizado na Bacia do Ribeirão Sozinha, em Goiás, há uma bomba para irrigar as margens do rio, além de diversos tonéis de óleo abandonados ao seu redor

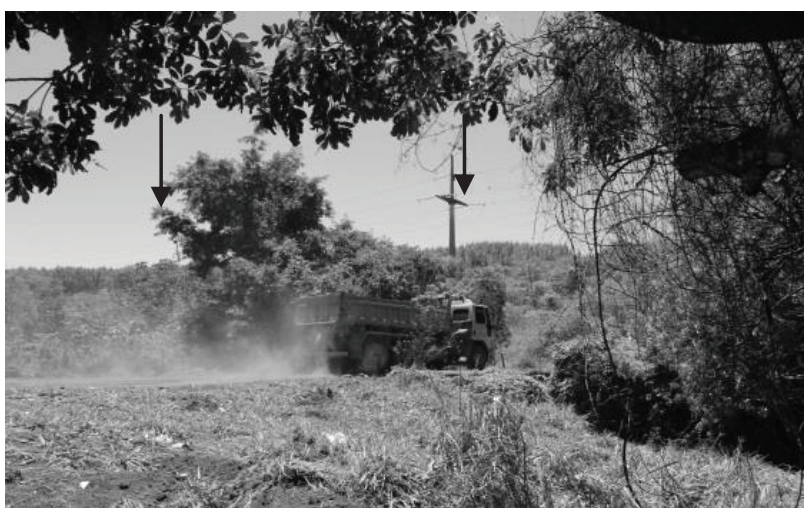

Figura 8 - Trecho GOI2, situado na Bacia do Ribeirão Sozinha, em Goiás, onde se pode ver o tráfego de veículos sobre o ribeirão

de Eucalyptus spp. (Figura 8, conforme as setas). O córrego é cortado por estrada rural de tráfego intenso e suas margens são instáveis e desflorestadas. Já o trecho GOI7 trata-se de uma área urbana situada na cidade de Bonfinópolis, cuja região abrange uma área muito degradada, uma vez que neste trecho houve a concentração da maior quantidade de atividades antrópicas impactantes dentre os pontos amostrais, segundo a matriz de Leopold. O riacho desta região foi soterrado por obra para a 


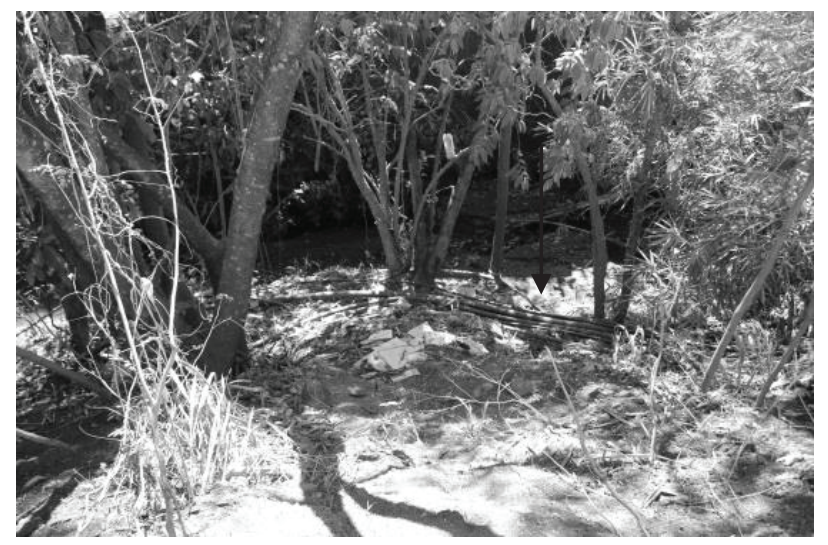

Figura 9 - Trecho GOI7, situado na Bacia do Ribeirão Sozinha, em Goiás, possui lixo (seta) e tubulações de esgoto

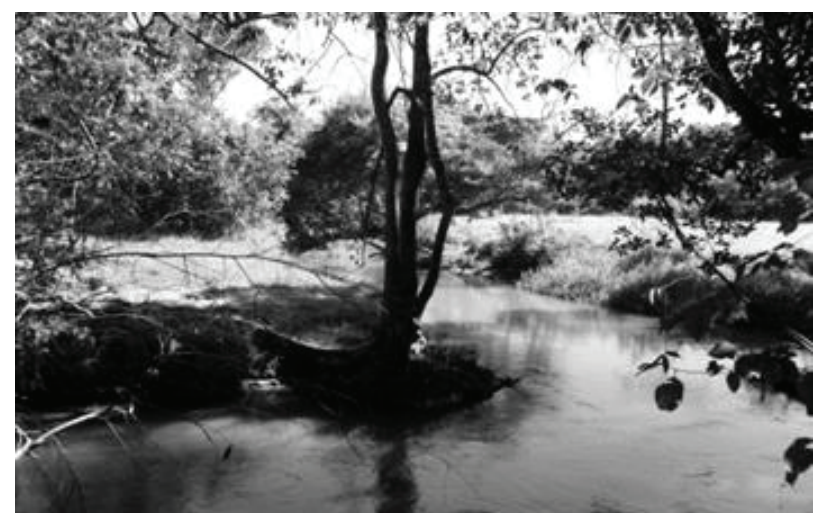

Figura 10 - Ponto GOI10.1, situado na Bacia do Ribeirão Sozinha, em Goiás, apresenta-se com mata ciliar desmatada

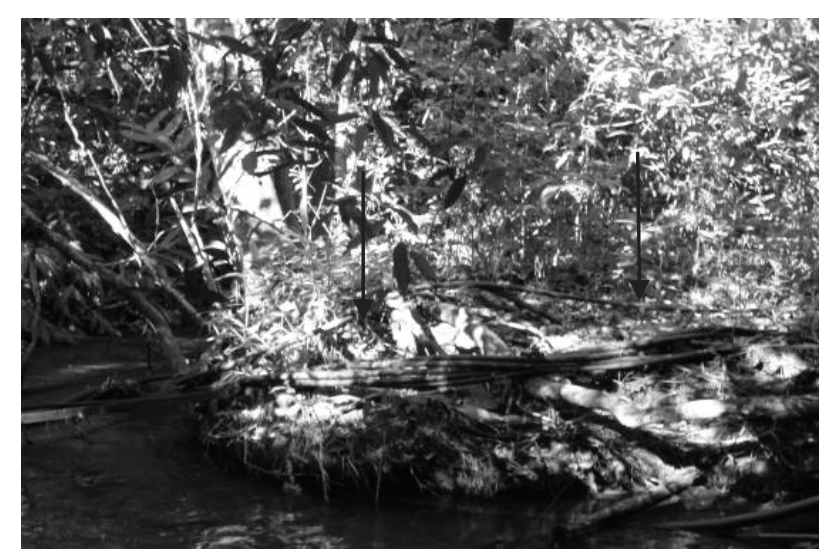

Figura 11 - No trecho GOI8.1, situado na Bacia do Ribeirão Sozinha, em Goiás, é possível ver tubulações (setas)

construção de uma avenida de grande tráfego de veículos (Figura 9). O riacho apresentava-se assoreado, havia lixo e erosões em sua margem.No ponto GOI10.1, o ribeirão possui mata ciliar estreita e em alguns pontos está completamente desflorestado (Figura 10), as margens possuem erosões e há a presença de lixo.

No trecho GOI8.1 há uma equidade entre a quantidade de impactos de "grande", "média" e "pequena" intensidade. Nesse ponto amostral o ribeirão foi canalizado para a construção de uma ferrovia, há diversas tubulações abandonadas no leito

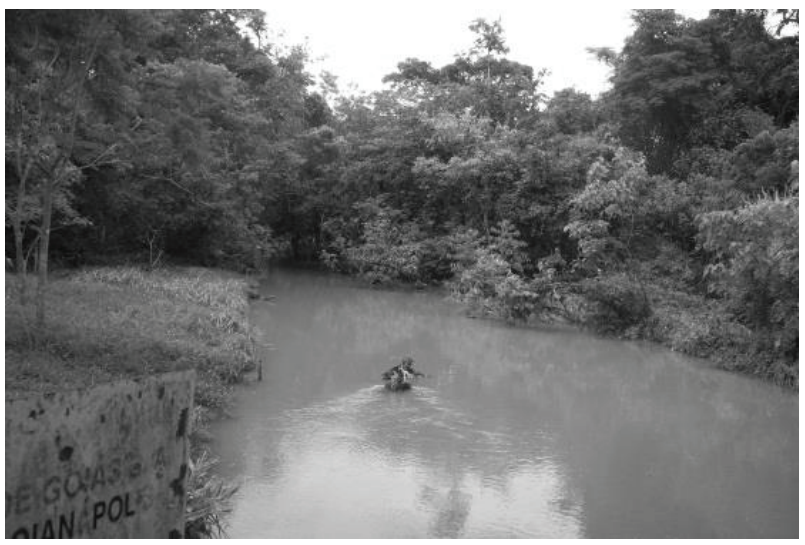

Figura 12 - O ribeirão do trecho Captação, situado na Bacia do Ribeirão Sozinha, em Goiás, possui as margens desmatadas e está represado

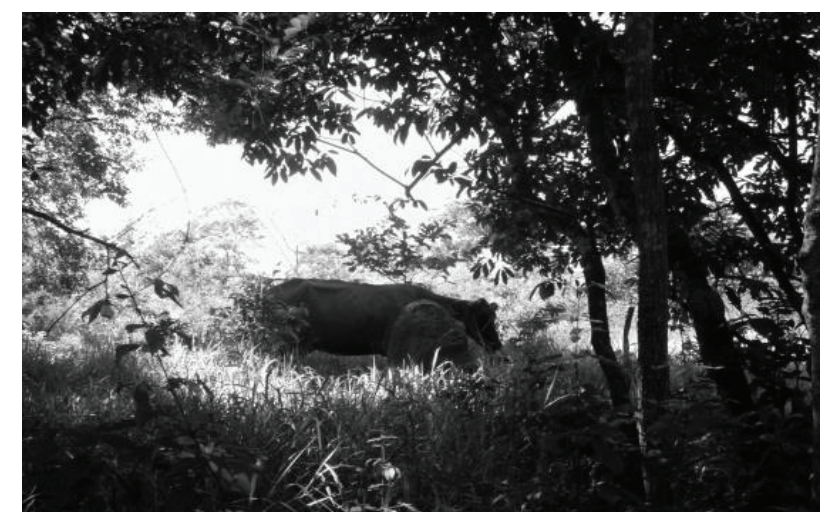

Figura 13 - Trecho GOI9.1, situado na Bacia do Ribeirão Sozinha, em Goiás, a atividade de pecuária às margens do ribeirão

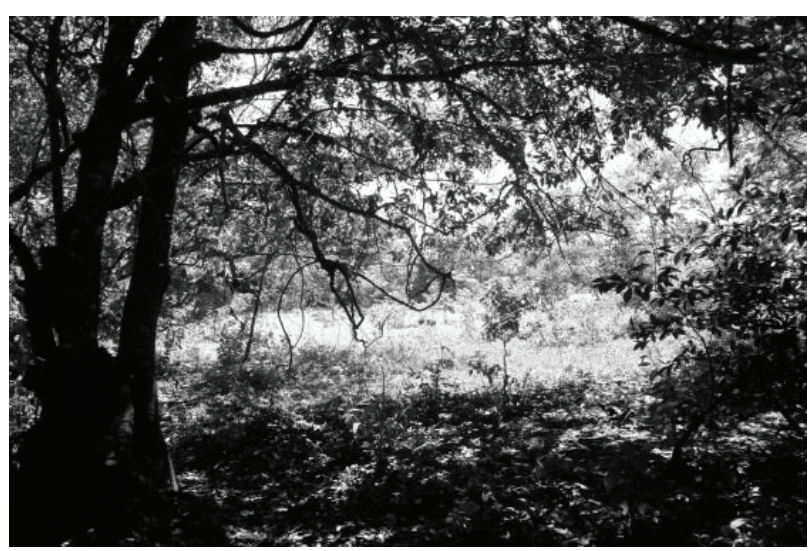

Figura 14 - Trecho GOI11.1, situado na Bacia do Ribeirão Sozinha, em Goiás, apresenta-se com mata ciliar desmatada

do corpo hídrico, utilizadas ou para o despejo de efluentes ou para o bombeamento de água; a determinação correta de seu uso não pode ser realizada (Figura 11).

Nos pontos amostrais GOI9.1, GOI11.1 e "Captação", a maioria dos impactos antrópicos foram considerados de "média" ou "pequena" intensidade, pois esses trechos estão em região agropecuária. O Ribeirão Sozinha, no trecho Captação, possui barramentos (Figura 12), há a presença de erosões e suas margens apresentam-se desmatadas. Já no trecho GOI9.1 há desmatamento 
e as margens estão assoreadas e erodidas(Figura 13).

O ponto GOI11.1 foi o que menos apresentou impactos entre todos os pontos avaliados pela matriz, apesar de esse trecho ser uma região de pastagem e o ribeirão estar com margens desflorestadas (Figura 14).

Continuando o diagnóstico ambiental, agora pela aplicação do protocolo de avaliação rápida da diversidade de habitats, verificou-se que as pontuações variaram de 18 a 74 (Tabela 3). Dos trechos visitados, $33,3 \%$ se enquadraram em "naturais" e $66,7 \%$ se encontram "alterados" ou "impactados".

Tabela 3 - Resultado da aplicação do protocolo de avaliação rápida na bacia do Ribeirão Sozinha, em Goiás

\begin{tabular}{l|l|l}
\hline Trecho & Pontuação & Situação Ambiental \\
\hline G0I1 & 37 & Impactado \\
\hline G0I2 & 55 & Alterado \\
\hline G0I3 & 65 & Natural \\
\hline G0I4 & 74 & Natural \\
\hline G0I5 & 46 & Alterado \\
\hline G0I6 & 55 & Alterado \\
\hline G0I7 & 18 & Impactado \\
\hline G0I8.1 & 65 & Natural \\
\hline G0I9.1 & 53 & Alterado \\
\hline G0I10.1 & 48 & Alterado \\
\hline G0I11.1 & 66 & Natural \\
\hline Captação & 52 & Alterado \\
\hline
\end{tabular}

As maiores pontuações obtidas na situação ambiental "natural” foram as dos pontos GOI3, GOI4 (Figura 3), GOI8.1 (Figura 11) e GOI11.1 (Figura 14), situados em áreas de agropecuária. Nestes trechos, as melhores pontuações foram dadas na primeira parte do protocolo. Esses trechos tiveram melhores pontuações em relação às características da água, do sedimento e do tipo de fundo.

A classificação dos trechos em "alterados" se deu em decorrência das pontuações nos parâmetros que correspondem à situação dos habitats, especialmente nos tipos de substrato (GOI6, GOI9.1 e GOI10.1), nos depósitos sedimentares ou lama (GOI2, GOI6) e na estabilidade das margens (Captação). As principais modificações se deram em função das alterações no canal do ribeirão, no qual os trechos apresentavam-se com cerca de $80 \%$ ou mais das margens do ribeirão modificadas (GOI2; GOI5, Figura 6; GOI6; GOI9; GOI10.1, Figura 10 e Captação), devido à retificação para pontes e ao desmatamento.

Somente dois trechos foram considerados "impactados", o que se deu principalmente devido às pontuações baixas nos parâmetros "depósitos de lama" e "estabilidade das margens", causados pelo assoreamento e pelas erosões. Os três trechos possuíam alterações no canal do ribeirão ocasionados pelo represamento (GOI1, Figura 5), pelas canalizações (GOI7),retificações e pela construção de pontes (GOI7, Figura 9). No aspecto "presença e extensão da mata ciliar", os três pontos amostrais possuíam alteração ou total degradação da área de preservação permanente para fins de agricultura ou pastagem.

Após a aplicação do protocolo, notou-se que a maioria dos trechos em estudo estava inserido em região agropecuária e que a degradação na qualidade ambiental deles se intensificava na medida em que a intensidade dessas atividades aumentava. Além disso, essa informação está em concordância com o que foi verificado no mapa de uso do solo e também com a matriz de impacto. Assim, notou-se a possibilidade destes corpos hídricos virem a sofrer mais alterações negativas pelo uso intensivo das atividades agrícolas e pecuárias.

Do mesmo modo, os protocolos foram instrumentos úteis que levaram em consideração a análise integrada dos ecossistemas lóticos,por meio de uma metodologia fácil, simples e viável para a aplicação por pessoas treinadas (RODRIGUES; CASTRO, 2008). De acordo com Firmino et al. (2011), os protocolos facilitam a tomada de decisão em relação aos problemas identificados durante a avaliação.

Rodrigues e Castro (2008a) destacam a possibilidade de avaliação de vários pontos de monitoramento ao longo de uma bacia hidrográfica, ressaltando que a aplicação é de baixo custo financeiro e que a obtenção de respostas a respeito do ambiente estudado é rápida. Por estas e outras vantagens Callisto et al. (2002) afirmam que esta ferramenta pode ser utilizada em qualquer programa de monitoramento ambiental. Esse fato foi constatado nesta pesquisa, uma vez que a bacia em estudo é extensa e havia o interesse de realizar a amostragem em trechos distribuídos ao longo de toda a bacia, de maneira rápida e financeiramente acessível.

Nesta pesquisa, o emprego da matriz foi viável, pois de fácil aplicação e adaptação para o levantamento e a avaliação dos impactos ao meio ambiente, sendo possível ter uma rápida obtenção e visualização do resultado (BARBOSA; DINIZ, 2010). Observou-se uma diminuição na qualidade do ambiente a partir da proximidade dos trechos amostrais com a maior concentração de atividades antrópicas impactantes.

Além disso, pode-se notar que a avaliação do uso do solo e o detalhamento dos principais e possíveis impactos nos recursos hídricos foram suficientes para levantar os principais impactos sofridos pela bacia e para compreender como eles estão inter-relacionados. O emprego das geotecnologias é interessante, pois é feito sem a necessidade de visita a campo, o que diminui os custos do monitoramento ambiental. Ressalta-se, também, que a aplicação do protocolo e da matriz foram importantes por confirmarem as informações obtidas no diagnóstico de uso do solo, pois demostraram que a situação ambiental da bacia e dos corpos hídricos estava intimamente relacionada com atividades de agricultura e pecuária.

Ao se avaliar conjuntamente os resultados do protocolo com a matriz de Leopold, observam-se situações como as ocorridas no ponto GOI1, considerado impactado, que obteve doze impactos no total, de acordo com a avaliação da matriz, sendo a maioria deles de "grande" e "pequena" intensidade. Já o ponto GOI3 obteve treze impactos de "grande" e "pequena" intensidade, mas foi considerado "natural" pelo protocolo. Situações como essas mostram que a utilização da matriz avalia os impactos de maneira global (na bacia) e o protocolo de maneira 
local (aspectos do ecossistema aquático). Isso pode significar que, muitas vezes, o ambiente pode estar degradado em âmbito local e preservado no global, e vice-versa. Assim, pode-se notar que a adaptação da matriz não é a ideal, principalmente se em conjunto com o protocolo, pois cada uma avalia os impactos em escalas diferentes.

Situações como essa também podem ter ocorrido pelo fato de a matriz ser visualmente orientada. Assim, sugere-se uma melhor adaptação desta, com o intuito de direcionar melhor a agregação das pontuações em termos de magnitude e importância, evitando uma generalização dos resultados. Outra sugestão seria uma adaptação que indicasse um resultado final do nível de impacto em cada trecho avaliado. Isso permitiria determinar mais precisamente a situação ambiental de cada região, o que facilitaria o monitoramento ambiental e a previsibilidade da futura situação ambiental da região. Um resultado final indicaria em que intensidade as medidas de preservação e gestão ambiental devem ser direcionadas para cada trecho da bacia, o que serviria como um parâmetro para ver como as ações de gestão ambiental estão evoluindo.

De maneira geral, esta pesquisa concorda com os resultados encontrados no trabalho de Padovesi-Fonseca et al. (2010), em que a aplicação conjunta dos protocolos de avaliação rápida e a aplicação de uma matriz de Leopold permitiram a identificação e a avaliação da magnitude dos impactos, mas não quando o autor afirma que a aplicação da matriz não foi subjetiva.

A avaliação integrada das atividades antropogênicas, propiciada pela avaliação por meio da matriz e da análise do uso do solo em conjunto com os resultados do protocolo, permitiu observar em que sentido as ações de planejamento e gestão ambiental devem ser direcionadas. Além disso, Padovesi-Fonseca et al. (2010) destacam a importância da avaliação de métodos conjuntos com o objetivo de evitar a interpretação precipitada de informações. Os autores afirmam que a utilização de métodos integrados pode substituir adequadamente métodos onerosos, como as análises físico-químicas, permitindo que uma vasta malha de pontos de monitoramento seja estabelecida. Isso também foi verificado neste estudo, pois com apenas duas visitas a campo foi possível fazer um levantamento dos principais impactos sofridos pela bacia.

A facilidade e o baixo custo de métodos como os utilizados nesta pesquisa possibilitam que o monitoramento da qualidade ambiental das bacias hidrográficas e dos corpos hídricos contidos em uma bacia sejam feitos em períodos curtos e em uma ampla variedade de áreas em uma bacia. Isso é um benefício no sentido de viabilizar a gestão ambiental e territorial de bacias hidrográficas brasileiras.

No Brasil, principalmente em pequenas bacias, é notória a carência de informações e a ausência de registros históricos a respeito da degradação ambiental sobre os recursos hídricos. A insuficiência de ações, de políticas públicas e de metodologias que possibilitem a gestão ambiental em bacias hidrográficas, entre outros fatores, dificulta mà gestão dos recursos hídricos o tornar-se uma atividade corrente na realidade brasileira.

Assim, estudos como este são relevantes no sentido de trazer informações sobre métodos que facilitem a gestão de recursos hídricos no Brasil, como os utilizados nesta pesquisa.
Os dados e as metodologias aqui utilizados podem ser empregados como um direcionamento para o emprego de políticas públicas e para a atuação dos órgãos competentes, com o intuito de auxiliar a gestão dos recursos hídricos de bacias hidrográficas brasileiras.

\section{CONCLUSÃO}

Pode-se destacar que a avaliação de uso do solo, apesar de feita de uma maneira geral, contemplou os principais usos que têm afetado tanto a bacia quanto os recursos hídricos. Pode-se notar que a utilização da matriz foi fundamental para elencar a intensidade dos impactos ambientais em cada trecho. A utilização do protocolo, da matriz e do mapa de uso do solo permitiu afirmar que a agricultura e a pecuária são as atividades antrópicas que mais afetam a bacia, pois suas consequências causam um declínio na qualidade ambiental dos rios e uma redução da integridade ambiental da bacia. Pode-se ressaltar que há uma complementariedade entre as metodologias utilizadas e que essa associação permitiu um maior detalhamento do estado geral de cada trecho avaliado e, embora haja a necessidade de adaptar a matriz de Leopold, a utilização conjunta pode ser uma opção viável para o monitoramento ambiental e para a gestão territorial e ambiental das bacias.

Os resultados obtidos nesta pesquisa indicam ser de fundamental importância haver uma melhor gestão dos recursos naturais da bacia hidrográfica do Ribeirão Sozinha, porque a maioria dos trechos amostrais encontra-se impactado em algum nível pelas atividades antrópicas, que podem estar gerando impactos ecossistêmicos. A gestão dos recursos ambientais da bacia propiciaria o uso sustentável dos recurso se evitaria problemas futuros relacionados à qualidade e disponibilidade de água, notadamente para o abastecimento humano.

\section{AGRADECIMENTOS}

Os autores agradecem a CAPES pela bolsa de mestrado, ao CNPQ (Processo no 477857/2012-4) e à FAPEG (Processo $\mathrm{n}^{\mathrm{o}}$ 201210267001192) pelo financiamento do projeto e à Saneago pela disponibilização de dados.

\section{REFERÊNCIAS}

BARBOSA, A. C.; DINIZ, H. N. Controle de processo erosivo provocado por rompimento de adutora na serra da Mantiqueira, SP, Brasil. Ciência Florestal, v. 20, n. 4, 2010.

BONNET, B. R. P. et al. Ampliação de ambientes ripários como alternativa às reservas legais: conciliando política florestal e conservação dos recursos hídricos no bioma cerrado. Boletim Goiano de Geografia, v. 27 n. 1 p. 97-115, 2007.

CALLISTO, M. et al. Aplicação de um protocolo de avaliação rápida da diversidade de habitats em atividades de ensino e 
pesquisa (MG-RJ). Acta Limnologica Brasiliensis, v. 14, n. 1, p. 91-98, 2002.

COSTA E SILVA, D.; MATTOS, A. Diagnóstico socioeconômico e ambiental em microbacia hidrográfica localizada em um núcleo de desertificação. Caminhos de Geografia, v. 14, n. 45, 2013.

DILL, J. R. P. Gestão ambiental em bacias hidrográficas. 2007. 125 f. Tese (Doutorado) - Universidade Federal de Santa Maria, Santa Maria, RS, 2007.

FERNANDES, M. C. et al. Influência do uso do solo na qualidade de água na microbacia Glória, Macaé, Rio de Janeiro. Engenharia Ambiental: Pesquisa e Tecnologia, v. 8, n. 2, 2011.

FINOTTI, A. et al. Monitoramento: recursos hidricos em áreas urbanas. São Paulo: EDUSP, 2009.

FIRMINO, P. F. et al. Diagnóstico da integridade ambiental de trechos de rios localizados no município de Ipameri, Sudeste do Estado de Goiás, através de um protocolo de avaliação rápida. Brazilian Journal of Aquatic Science and Technology, v. 15, n. 2, p. $1-12,2011$.

GOMES, H. F. B. et al. Balanço de radiação em diferentes biomas no estado de São Paulo mediante imagens Landsat 5. Geociências, São Paulo, v. 28, n. 2, p. 153-164, 2009.

IBGE - Instituto Brasileiro de Geografia e Estatística. Levantamento sistemático da produção agrícola. Disponível em: <http://www1.ibge.gov.br/home/estatistica/indicadores/ agropecuaria/lspa/lspa_201308.pdf>. Acesso em: 6 jan. 2014.

IMB - Instituto Mauro Borges. Goiás em Dados 2012. Disponível em: <http://www.seplan.go.gov.br/sepin/down/goiascn2012. pdf $>$. Acesso em: 6 jan. 2014.

LEITE, et al. Sensoriamento remoto aplicado ao mapeamento da dinâmica do uso do solo na bacia do rio Pacuí, no norte de minas gerais, nos anos de 1989, 1999 e 2009. RDG-Revista do Departamento de Geografia-USP, v. 23, p. 217-231, 2012.

LUCAS, L. M; CUNHA, S. B. Rede de drenagem urbana em área tropical: mudanças na morfologia do canal e níveis de poluição das águas-Rio dos Macacos-Rio de Janeiro-RJ. GEOUSP: espaço e tempo, n. 22, p. 39-64, 2011.

OLIVEIRA-FILHO, E.C.; LIMA, J. E. F. W. Potencial de impacto da agricultura sobre os recursos hídricos na região do Cerrado. Documento n. 56, EMBRAPA, Planaltina-DF, p.50, 2002.

PADOVESI-FONSECA, C. et al. Diagnóstico da sub-bacia do ribeirão Mestre d'Armas por meio de dois métodos de avaliação ambiental rápida, Distrito Federal, Brasil Central. Revista Ambiente e Água, v. 5, n. 1, 2010.
RODRIGUES, A. S. L.; CASTRO, P.T.A. Protocolos de avaliação rápida: instrumentos complementares no monitoramento dos recursos hídricos. Revista Brasileira de Recursos Hídricos, v. 13, n. 1, p. 161-170, 2008.

RODRIGUES, A. S. L.; CASTRO, P. T. A. Adaptation of rapid assessment protocol for river son rocky meadows. Acta Limnologica Brasiliensia, v. 20, n. 4, p. 291-303, 2008a.

SANCHÉZ, L. E. Avaliação de impacto ambiental: conceitos e métodos. São Paulo: Oficina de Textos, 2006.

SANO, E. E. et al. Land cover mapping of the tropical savanna region in Brazil. Environmental monitoring and assessment, v. 166, n. 1-4, p. 113-124, 2010.

SOARES, W. L.; PORTO, M. F. Atividade agrícola e externalidade ambiental: uma análise a partir do uso de agrotóxicos no cerrado brasileiro. Ciência \& Saúde Coletiva, v. 12, n. 1, p. 131-143, 2007.

SOUZA, J. C.; LIMA, C. V. Avaliação do potencial à erosão laminar da bacia do Ribeirão Sozinha (GO). Acta Geográfica, v. 7, n. 14, 2013.

SOUZA, V. C. B.; MORAES, L. R. S.; BORJA, P. C. Déficit na drenagem urbana: buscando o entendimento e contribuindo para a definição. Revista Eletrônica de Gestão e Tecnologias Ambientais, v. 1, n. 2, p. 162-175, 2013.

SUGA, C. M.; TANAKA, M. Influence of a forest remnant on macro invertebrate communities in a degraded tropical stream. Hydrobiologia, v. 703, n. 1, p. 203-213, 2013. 